\title{
Early Initiation of Post-Pyloric Feeding in Patients with Major Burns: Experience in Taiwan Formosa Water Park Dust Explosion Disaster
}

\author{
Yu-Chen Tseng, ${ }_{1}^{1}$ Bao-Chung Chen, ${ }^{1}$ Chun-Ting Chen, ${ }^{1}$ Yu-Ching Chou, ${ }^{2}$ \\ Niann-Tzyy Dai, ${ }^{3}$ Peng-Jen Chen, ${ }^{1}$ Tien-Yu Huang, ${ }^{1}$ Yu-Lueng Shih, ${ }^{1}$ \\ Wei-Kuo Chang, ${ }^{1}$ Tsai-Yuan Hsieh ${ }^{1}$ and Jung-Chun Lin ${ }^{1}$ \\ ${ }^{1}$ Division of Gastroenterology and Hepatology, Department of Internal Medicine, Tri-Service General Hospital,
National Defense Medical Center, Taipei, Taiwan
${ }^{2}$ School of Public Health, National Defense Medical Center, Taipei, Taiwan
${ }^{3}$ Division of Plastic and Reconstructive Surgery, Department of Surgery, Tri-Service General Hospital, National
Defense Medical Center, Taipei, Taiwan
}

Early initiation of enteral nutrition improves clinical outcomes in critical patients with serious burns. Postpyloric tube feeding is a valuable therapeutic option for severely burned patients with poor gastric emptying. How early post-pyloric feeding can be initiated to provide more benefits to patients has not yet been examined. A fire erupted at a recreational water park in New Taipei City, Taiwan, on June 27, 2015. The results of early initiation versus delayed post-pyloric feeding in severely burned patients in this masscasualty incident were compared. Door-to-post-pyloric feeding time $\leq 24 \mathrm{~h}$ was considered as early postpyloric feeding (EPF) and that $>24 \mathrm{~h}$ was considered as delayed post-pyloric feeding (DPF). Thirteen patients with severe burn injuries ( $>40 \%$ of the total body surface area) were assigned to undergo either EPF (five patients) or DPF (eight patients). This study is a "fortuitously controlled" study, and the authors were able to formulate and test whether EPF is better than DPF by comparing the two groups. In patients in the EPF, the intake of calories increased rapidly and was maintained throughout the study period. In addition, rapid restoration of plasma magnesium concentrations as well as pronounced recovery of platelet count in the EPF group was observed. In conclusion, our findings indicate that the time from injury to the onset of post-pyloric feeding is crucial, and EPF allows for the administration of calculated caloric needs. Therefore, EPF can be successfully initiated with beneficial outcomes of nutritional reconstruction in severely burned patients.

Keywords: burns; dust explosion disaster; early enteral nutrition; nutritional reconstruction; post-pyloric feeding Tohoku J. Exp. Med., 2019 February, 247 (2), 111-118. (C) 2019 Tohoku University Medical Press

\section{Introduction}

Severe burns initiate a chain of inflammatory reactions, such as dehydration, extensive loss of tissues, acid-base disturbance, hormonal imbalance, hypoperfusion, shock, organ dysfunction, and infectious diseases (Raff et al. 1997). If the burn size is $>20 \%$ of the total body surface area (TBSA), a hypermetabolic response occurs with increased resting energy expenditure, causing high intensity of stress, enhanced catabolism, and rapid loss of lean body mass (Raff et al. 1997; Sheridan 2002; Vicic et al. 2013). The most fearful complication of burns with a high mortality rate is multi-organ failure. In such cases, late introduction of enteral nutrition is one of the risk factors leading to poor prognosis and death (Vicic et al. 2013).
As is broadly reported in the literature, early administration of enteral nutrition has several benefits, including alleviating the stress response, abating hypermetabolism, and improving patient outcome, compared to parenteral nutrition in severely burned patients (Andel et al. 2001; Chen et al. 2007; Mosier et al. 2011). However, severely burned patients may experience intolerance to enteral feeding due to poor digestion (Lavrentieva et al. 2014; Trexler et al. 2014). Moreover, most burned patients require analgesic agents with high-dose opioids that cause hypomotility of the gastrointestinal tract. Therefore, postpyloric tube feeding is a valuable therapeutic option for major burned patients with delayed gastric emptying (Sefton et al. 2002; Stroud et al. 2003). Although early enteral nutrition has improved prognosis in burns patients,

Received December 17, 2018; revised and accepted February 7, 2019. Published online February 19, 2019; doi: 10.1620/tjem.247.111.

Correspondence: Jung-Chun Lin, M.D., Ph.D., Division of Gastroenterology and Hepatology, Department of Internal Medicine,

Tri-Service General Hospital, National Defense Medical Center, No. 325, Sec. 2, Cheng-gong Rd., Neihu, Taipei 11490, Taiwan.

e-mail: doc10506@gmail.com 
whether early post-pyloric feeding (EPF) is beneficial to severely burned patients remains to be answered.

In June 2015, the gastroenterologists at the Tri-Service General Hospital, a medical teaching hospital belonging to the National Defense Medical Center in Taipei, Taiwan, differed in their opinions about the benefits of EPF in a mass-casualty incident with multiple burns victims. Therefore, in this study, we investigated the effects of EPF in burns patients.

\section{Methods}

\section{Patients}

On June 27, 2015, a fire erupted when a flammable starch-based powder exploded at a recreational water park in New Taipei City, Taiwan, injuring 499 people, with 199 in a critical condition. The injured patients were treated in $>40$ hospitals across Taiwan. A total of 61 patients were treated at the Department of Emergency Medicine of the Tri-Service General Hospital, Taipei, Taiwan. Thirty patients experienced severe burn injuries ( $>40 \%$ TBSA) and required to be transferred to the burns intensive care unit (ICU). Door-to-postpyloric feeding time (h) was defined as the time interval between the patient's arrival at the emergency department and endoscopic postpyloric intubation. Door-to-post-pyloric feeding time $\leq 24 \mathrm{~h}$ was considered EPF and that $>24 \mathrm{~h}$ was considered as delayed postpyloric feeding (DPF). Thirteen patients were assigned to undergo either EPF or DPF: five patients underwent EPF and the remaining eight underwent DPF (Fig. 1). Administration of EPF or DPF solely depended on the gastroenterologist who was on call and was independent of the patient's condition; this is because the hospital's eight attending gastroenterologists had strongly varying viewpoints on EPF. Therefore, this study is a "fortuitously controlled" study, and we were able to formulate and test whether EPF is better than DPF by comparing the two groups. The Institutional Review Board of the Tri-Service General Hospital approved the collection and analysis of clinical data (IRB: 2-105-05-008). Follow-up for each patient started at the beginning of the hospitalization period, and follow-up for the entire study.

Assessment of clinical parameters

The "rule of nines" was used to estimate the degree of the burn (Hettiaratchy and Papini 2004). Laboratory examinations, including complete blood count, as well as measurement of plasma electrolytes [sodium $(\mathrm{mmol} / \mathrm{L})$, potassium $(\mathrm{mmol} / \mathrm{L})$ and magnesium $(\mathrm{mg} / \mathrm{dL})$ ], plasma glucose $(\mathrm{mg} / \mathrm{dL})$, aspartate aminotransferase (AST, IU/L), creatinine $(\mathrm{mg} / \mathrm{dL})$, albumin $(\mathrm{g} / \mathrm{dL})$, and procalcitonin $(\mathrm{ng} / \mathrm{mL})$ levels, were conducted on admission and followed up once a week. Nutrition status, body weight, and body mass index (BMI) in both groups were obtained from medical records. The Harris-Benedict equation was used to determine basal energy expenditure and estimate the total caloric requirement (El-Solh 2004).

Procedure

The post-pyloric tube (12 French, 114-cm long, polyurethane feeding tube with stylet, CORFLO ${ }^{\circledR}$, CORPAK MedSystems. Inc., Buffalo Grove, USA) was endoscopically placed using the "drag and pull" technique (Chang et al. 2005). Before the procedure, two 3.0 nylon suture-tied knots were created on both sides of the tube at 0.5 $\mathrm{cm}$ intervals. The feeding tube was flushed with water. The outer wall of the feeding tube was lubricated with $2 \%$ xylocaine jelly, introduced through the nostril, and delivered into the stomach. Furthermore, a standard single-channel endoscope (GIF Q260, Olympus, Tokyo, Japan) was intubated into the stomach. A biopsy forceps was inserted into the working channel of the endoscope and used to firmly grasp the tie. The feeding tube was pulled to pass through the pyloric ring into the second or third portion of the duodenum. After the endoscope was inserted as further as possible beyond the pylorus, the biopsy forceps holding the suture tie at the tip of the feeding tube was further extended. The biopsy forceps were then opened to release the suture. Meanwhile, the stylet was maintained in place to stiffen the feeding tube. To avoid its retrograde migration, the endoscope was slowly withdrawn into the stomach, esophagus, and out of the patient's mouth. After the stylet was removed, the procedure was completed. All procedures were per-

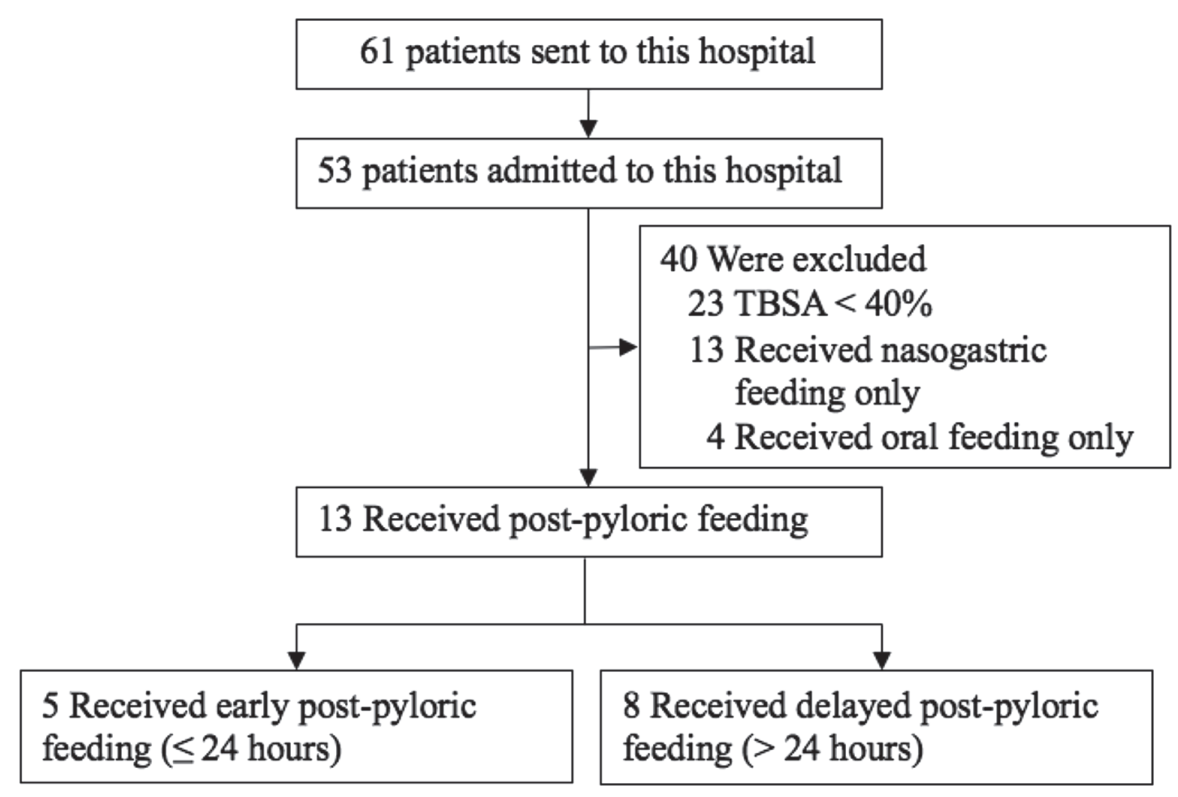

Fig. 1. Flow chart of study participants. 
formed at the bedside in the critical care unit.

Statistical analysis

Statistical analyses were performed using SPSS software version 20.0 (IBM, Armonk, NY, USA). The independent Student's test and the Chi-square test were used to compare continuous and categorical data between the groups. A $p$ value of $<0.05$ was considered sta- tistically significant for all tests.

\section{Results}

Study population

The size of the burned area was $50 \%$ in 5 patients, $60 \%$ in 4 patients, $70 \%$ in 1 patient, and $80 \%$ in 3 patients. There were no significant differences in age $(24 \pm 4$ vs. 22

Table 1. Baseline characteristics of the patients.

\begin{tabular}{|c|c|c|c|}
\hline Characteristics & $\begin{array}{c}\text { Early Post-Pyloric Feeding } \\
\text { Group }(\mathrm{n}=5)\end{array}$ & $\begin{array}{c}\text { Delayed Post-Pyloric Feeding } \\
\text { Group }(\mathrm{n}=8)\end{array}$ & $\mathrm{p}$ value \\
\hline Sex, n (\%) & & & 0.293 \\
\hline Female & $2(40)$ & $6(75)$ & \\
\hline Male & $3(60)$ & $2(25)$ & \\
\hline Age, $\mathrm{M} \pm \mathrm{SD}$ (range) & $24 \pm 4(19-28)$ & $22 \pm 2(19-25)$ & 0.130 \\
\hline BMI, $\mathrm{M} \pm \mathrm{SD}$ & $23.04 \pm 3.24$ & $21.69 \pm 1.82$ & 0.350 \\
\hline $\begin{array}{l}\text { Tube feeding period } \\
\text { (days), } \mathrm{M} \pm \mathrm{SD}\end{array}$ & $82.0 \pm 9.6$ & $83.3 \pm 50.7$ & 0.958 \\
\hline $\mathrm{TBSA}, \mathrm{M} \pm \mathrm{SD}(\%)$ & $70.4 \pm 10.5$ & $56.4 \pm 10.4$ & $0.014 *$ \\
\hline Leukocyte count, $\mathrm{M} \pm \mathrm{SD}$ & $29.59 \pm 9.74$ & $26.98 \pm 8.97$ & 0.631 \\
\hline$\left(10^{9} / \mathrm{L}\right)$ & & & \\
\hline $\begin{array}{l}\text { Hemoglobin, } \mathrm{M} \pm \mathrm{SD} \\
(\mathrm{g} / \mathrm{dL})\end{array}$ & $18.90 \pm 2.94$ & $16.73 \pm 2.57$ & 0.187 \\
\hline $\begin{array}{l}\text { Platelet count, } \mathrm{M} \pm \mathrm{SD} \\
\left(\times 10^{3} / \mu \mathrm{L}\right)\end{array}$ & $232.80 \pm 77.44$ & $251.25 \pm 50.67$ & 0.611 \\
\hline $\mathrm{AST}, \mathrm{M} \pm \mathrm{SD}(\mathrm{IU} / \mathrm{L})$ & $42.00 \pm 15.80$ & $34.75 \pm 10.17$ & 0.331 \\
\hline Sodium, $\mathrm{M} \pm \mathrm{SD}(\mathrm{mmol} / \mathrm{L})$ & $133.80 \pm 4.49$ & $133.75 \pm 2.82$ & 0.981 \\
\hline $\begin{array}{l}\text { Potassium, } \mathrm{M} \pm \mathrm{SD} \\
(\mathrm{mmol} / \mathrm{L})\end{array}$ & $4.20 \pm 0.89$ & $3.74 \pm 0.62$ & 0.288 \\
\hline $\begin{array}{l}\text { Magnesium, } \mathrm{M} \pm \mathrm{SD} \\
(\mathrm{mg} / \mathrm{dL})\end{array}$ & $1.28 \pm 0.26$ & $1.20 \pm 0.19$ & 0.527 \\
\hline Albumin, $\mathrm{M} \pm \mathrm{SD}(\mathrm{g} / \mathrm{dL})$ & $2.04 \pm 0.51$ & $2.11 \pm 0.58$ & 0.823 \\
\hline $\begin{array}{l}\text { Procalcitonin, } \mathrm{M} \pm \mathrm{SD} \\
(\mathrm{ng} / \mathrm{mL})\end{array}$ & $1.27 \pm 0.51$ & $1.51 \pm 1.24$ & 0.765 \\
\hline
\end{tabular}

AST, aspartate aminotransferase; $\mathrm{BMI}$, body mass index; $\mathrm{M} \pm \mathrm{SD}$, mean \pm standard deviation; $\mathrm{TBSA}$, total body surface area.

$* \mathrm{p}<0.05$. 
\pm 2 years, $\mathrm{p}=0.293)$, baseline BMI $(23.04 \pm 3.24$ vs. 21.69 $\pm 1.82, \mathrm{p}=0.350)$, and the total period of post-pyloric feeding $(82.0 \pm 9.6$ vs. $83.3 \pm 50.7, p=0.958)$ between the EPF and DPF groups (Table 1).

\section{Caloric intake}

The calories provided per day in the EPF and DPF groups are presented in Fig. 2. There was an increase in the mean caloric intake throughout the 21-day period in both groups. When changes in absolute values were compared, the increase in the mean caloric intake was statistically significant in patients in the EPF group on days $4(p<0.001)$, $7(\mathrm{p}=0.005)$, and $14(\mathrm{p}<0.001)$ than in patients in the DPF group.

\section{Plasma magnesium level}

Hypomagnesemia is common after a burn injury due to losses in the exudates (Cunningham et al. 1987; Berger

\section{Total Energy}

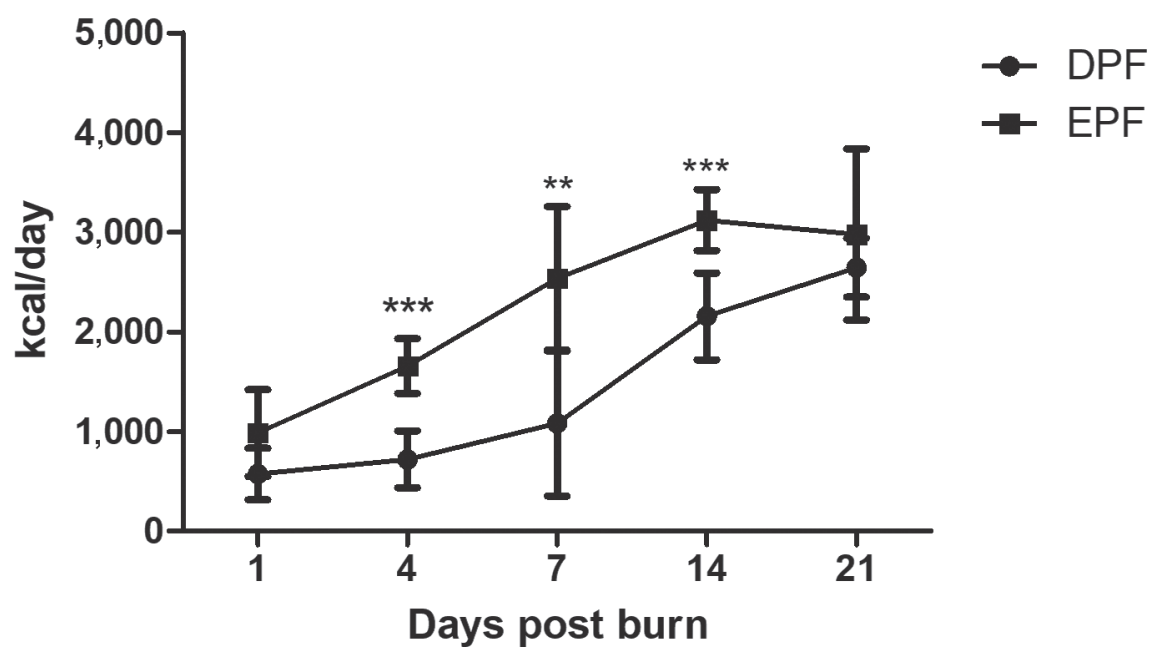

Fig. 2. Time-dependent changes in total energy intake.

The graphs show average total energy intake per day (kcal/day) in the early post-pyloric feeding (EPF) and delayed post-pyloric feeding (DPF) groups. Compared with the DPF group, the increase in mean caloric intake in the EPF group was statistically significant on days 4,7 , and 14 .

$* * p<0.01$ compared to the DPF group.

$* * * \mathrm{p}<0.001$ compared with the DPF group.

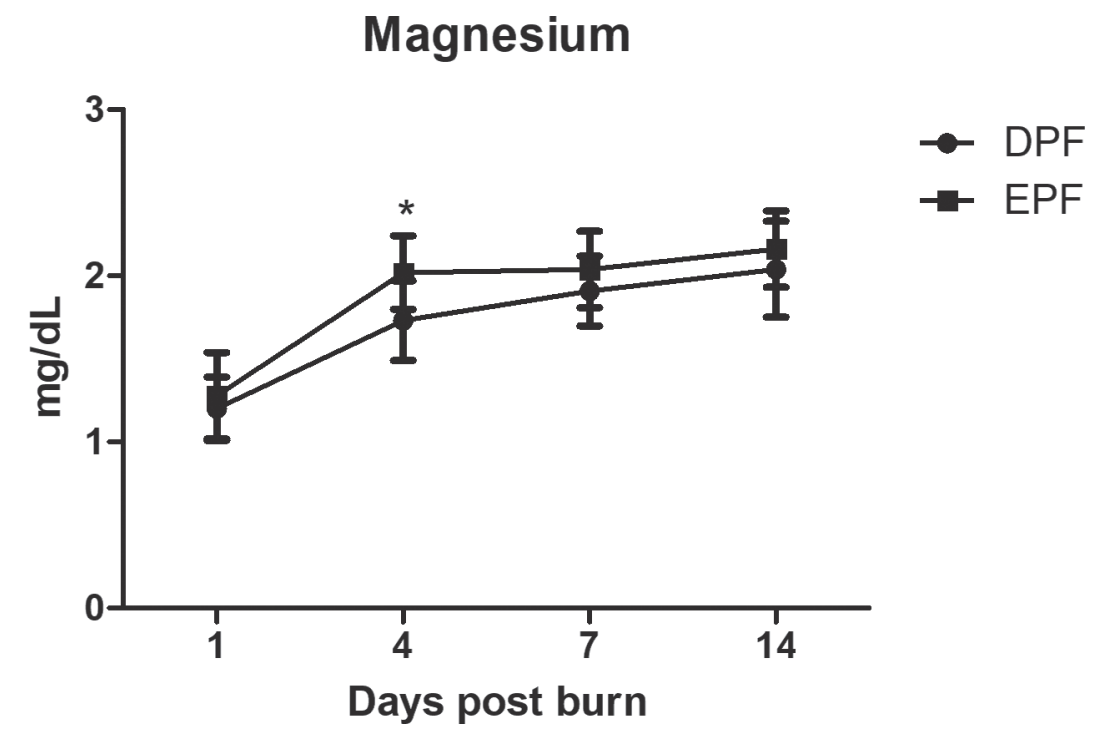

Fig. 3. Average plasma magnesium level change after burn injury.

On day 4 , a more rapid increase in the mean plasma magnesium level $(\mathrm{mg} / \mathrm{dL})$ was observed with significant difference in the EPF group compared with the DPF group.

$* \mathrm{p}<0.05$ compared with the DPF group. 
Table 2. Laboratory data change and nutrition status progress compare to day 1 in each study group.

\begin{tabular}{|c|c|c|c|c|}
\hline & $\begin{array}{l}\text { Early post-pyloric } \\
\text { feeding }(\mathrm{n}=5)\end{array}$ & $\mathrm{p}$ value & $\begin{array}{l}\text { Delayed post-pyloric } \\
\text { feeding }(\mathrm{n}=8)\end{array}$ & $\mathrm{p}$ value ${ }^{\mathrm{a}}$ \\
\hline \multicolumn{5}{|c|}{ Leukocyte count, } \\
\hline \multicolumn{5}{|c|}{$\mathrm{M} \pm \mathrm{SD}\left(10^{9} / \mathrm{L}\right)$} \\
\hline Day1 & $29.59 \pm 9.74$ & baseline & $26.98 \pm 8.97$ & baseline \\
\hline Day4 & $7.55 \pm 2.32$ & $0.005^{* *}$ & $4.52 \pm 1.96$ & $<0.001^{* * *}$ \\
\hline Day7 & $8.84 \pm 4.97$ & $0.012^{*}$ & $8.71 \pm 2.03$ & $0.001^{* *}$ \\
\hline Day14 & $14.35 \pm 3.90$ & 0.053 & $8.79 \pm 2.82$ & $<0.001^{* * *}$ \\
\hline \multicolumn{5}{|c|}{ Hemoglobin, } \\
\hline \multicolumn{5}{|c|}{$\mathrm{M} \pm \mathrm{SD}(\mathrm{g} / \mathrm{dL})$} \\
\hline Day1 & $18.90 \pm 2.94$ & baseline & $16.73 \pm 2.57$ & baseline \\
\hline Day4 & $10.22 \pm 0.96$ & $0.002^{* *}$ & $9.43 \pm 0.99$ & $<0.001^{* * *}$ \\
\hline Day7 & $10.26 \pm 0.95$ & $0.002^{* *}$ & $10.11 \pm 1.28$ & $<0.001^{* * *}$ \\
\hline Day14 & $9.28 \pm 0.49$ & $0.003^{* *}$ & $9.29 \pm 1.33$ & $<0.001^{* * *}$ \\
\hline \multicolumn{5}{|c|}{ Platelet count, } \\
\hline \multicolumn{5}{|c|}{$\mathrm{M} \pm \mathrm{SD}\left(\times 10^{3} / \mu \mathrm{L}\right)$} \\
\hline Day1 & $232.80 \pm 77.44$ & baseline & $251.25 \pm 50.67$ & baseline \\
\hline Day4 & $118.80 \pm 20.09$ & $0.028^{*}$ & $109.75 \pm 15.87$ & $<0.001^{* * *}$ \\
\hline Day7 & $204.60 \pm 95.39$ & 0.733 & $163.50 \pm 49.93$ & $0.004^{* *}$ \\
\hline Day14 & $431.40 \pm 162.92$ & 0.063 & $212.88 \pm 161.08$ & 0.467 \\
\hline \multicolumn{5}{|c|}{$\mathrm{AST}, \mathrm{M} \pm \mathrm{SD}(\mathrm{IU} / \mathrm{L})$} \\
\hline Day1 & $42.00 \pm 15.80$ & baseline & $34.75 \pm 10.17$ & baseline \\
\hline Day4 & $51.60 \pm 64.18$ & 0.787 & $37.38 \pm 16.42$ & 0.457 \\
\hline Day7 & $28.60 \pm 8.79$ & 0.149 & $34.25 \pm 16.25$ & 0.929 \\
\hline Day14 & $74.00 \pm 44.93$ & 0.250 & $103.63 \pm 73.64$ & $0.034^{*}$ \\
\hline \multicolumn{5}{|c|}{ Sodium, $\mathrm{M} \pm \mathrm{SD}$} \\
\hline \multicolumn{5}{|c|}{$(\mathrm{mmol} / \mathrm{L})$} \\
\hline Day1 & $133.80 \pm 4.49$ & baseline & $133.75 \pm 2.82$ & baseline \\
\hline Day4 & $144.20 \pm 5.45$ & $0.020^{*}$ & $140.00 \pm 3.51$ & $0.011^{*}$ \\
\hline Day7 & $145.60 \pm 4.88$ & $0.025^{*}$ & $145.50 \pm 3.85$ & $0.001^{* *}$ \\
\hline Day14 & $140.40 \pm 9.13$ & 0.172 & $140.88 \pm 7.62$ & $0.031^{* *}$ \\
\hline \multirow{2}{*}{\multicolumn{5}{|c|}{$\begin{array}{l}\text { Potassium, } \mathrm{M} \pm \mathrm{SD} \\
(\mathrm{mmol} / \mathrm{L})\end{array}$}} \\
\hline & & & & \\
\hline Day1 & $4.20 \pm 0.89$ & baseline & $3.74 \pm 0.62$ & baseline \\
\hline Day4 & $2.96 \pm 0.43$ & $0.028^{*}$ & $3.06 \pm 0.37$ & $0.016^{*}$ \\
\hline Day7 & $3.54 \pm 0.38$ & 0.203 & $3.41 \pm 0.40$ & 0.228 \\
\hline Day14 & $3.96 \pm 0.23$ & 0.587 & $3.80 \pm 0.41$ & 0.832 \\
\hline \multirow{2}{*}{\multicolumn{5}{|c|}{$\begin{array}{l}\text { Magnesium, } \mathrm{M} \pm \mathrm{SD} \\
(\mathrm{mg} / \mathrm{dL})\end{array}$}} \\
\hline & & & & \\
\hline Day1 & $1.28 \pm 0.26$ & baseline & $1.20 \pm 0.19$ & baseline \\
\hline Day4 & $2.02 \pm 0.22$ & $0.017^{*}$ & $1.73 \pm 0.24$ & $0.001^{* *}$ \\
\hline Day7 & $2.04 \pm 0.23$ & $0.003^{* *}$ & $1.91 \pm 0.21$ & $<0.001^{* * *}$ \\
\hline Day14 & $2.16 \pm 0.23$ & $0.002^{* *}$ & $2.04 \pm 0.29$ & $<0.001^{* * *}$ \\
\hline \multicolumn{5}{|c|}{ Albumin, $\mathrm{M} \pm \mathrm{SD}(\mathrm{g} / \mathrm{dL})$} \\
\hline Day1 & $2.04 \pm 0.51$ & baseline & $2.11 \pm 0.58$ & baseline \\
\hline Day4 & $3.06 \pm 0.29$ & $0.018^{*}$ & $3.06 \pm 0.49$ & $0.007^{* *}$ \\
\hline Day7 & $3.60 \pm 0.64$ & $0.006^{* *}$ & $3.70 \pm 0.33$ & $<0.001^{* * *}$ \\
\hline Day14 & $3.20 \pm 0.58$ & $0.035^{*}$ & $3.61 \pm 0.58$ & $0.001^{* *}$ \\
\hline \multicolumn{5}{|c|}{ Total Energy, $\mathrm{M} \pm \mathrm{SD}$} \\
\hline \multicolumn{5}{|l|}{ (cal/day) } \\
\hline Day1 & $984.00 \pm 435.98$ & baseline & $605.00 \pm 256.96$ & baseline \\
\hline Day4 & $1,656.00 \pm 273.64$ & $0.010^{*}$ & $780.00 \pm 314.23$ & $0.014^{* *}$ \\
\hline Day7 & $2,536.00 \pm 719.22$ & $0.017^{*}$ & $1,145.00 \pm 697.32$ & 0.068 \\
\hline Day14 & $3,120.00 \pm 305.94$ & $0.003^{* *}$ & $2,155.00 \pm 403.80$ & $<0.001^{* * *}$ \\
\hline Day21 & $2,976.00 \pm 858.65$ & $0.024^{*}$ & $2,718.00 \pm 346.49$ & $<0.001^{* * *}$ \\
\hline
\end{tabular}

AST, aspartate aminotransferase; $\mathrm{M} \pm \mathrm{SD}$, Mean \pm standard deviation. apaired t-test.

${ }^{*} \mathrm{p}<0.05, * * \mathrm{p}<0.01, * * * \mathrm{p}<0.001$. 
et al. 1997). At the baseline, plasma magnesium concentrations were lower than the normal range in both the EPF and DPF groups without statistical difference $(1.28 \pm 0.26$ vs. $1.20 \pm 0.19 \mathrm{mg} / \mathrm{dL}, \mathrm{p}=0.527)$. The largest average increase of magnesium in the EPF group was $68.8 \%$, while that in the DPF group was $70 \%$. However, comparison of the groups demonstrated the presence of a more rapid increase in mean magnesium concentrations with statistically significant differences $(p=0.049)$ on day 4 in the EPF group compared to the DPF group (Fig. 3, Table 2).

\section{Platelet count}

At the baseline, there was no difference in platelet count between the EPF and DPF groups (232.80 \pm 77.44 vs. $\left.251.25 \pm 50.67 \times 10^{3} / \mu \mathrm{L}, \mathrm{p}=0.611\right)$. A significant decline in platelet count was observed in both groups on day 4 of the treatment. Comparison of the groups indicated the pres- ence of a more pronounced ascent in platelet count on day 14 in the EPF group compared to the DPF group (431.40 \pm 162.92 vs. $212.88 \pm 161.08 \times 10^{3} / \mu \mathrm{L}, \mathrm{p}=0.037$ ) (Fig. 4 , Table 2).

\section{Clinical outcomes}

All the patients survived and were discharged. Overall, the median ICU stay was 34 days (range 20 to 85 days) in patients receiving EPF, and 40 days (range 18 to 85 days) for those receiving DPF, but the difference was not statistically significant. Similarly, there were short hospital days in EPF than DPF groups (132 \pm 23 vs. $144 \pm 70, \mathrm{p}=$ $0.729)$ but no static difference. Blood stream infection rate $(60.0 \%$ vs. $62.5 \%, \mathrm{p}=0.931)$, pneumonia rate $(40.0 \%$ vs. $37.5 \%, \mathrm{p}=0.931)$, and wound infection rate $(40.0 \%$ vs. $75.0 \%, \mathrm{p}=0.225)$ did not differ between the EPF and DPF groups (Table 3 ).

\section{Platelet count}

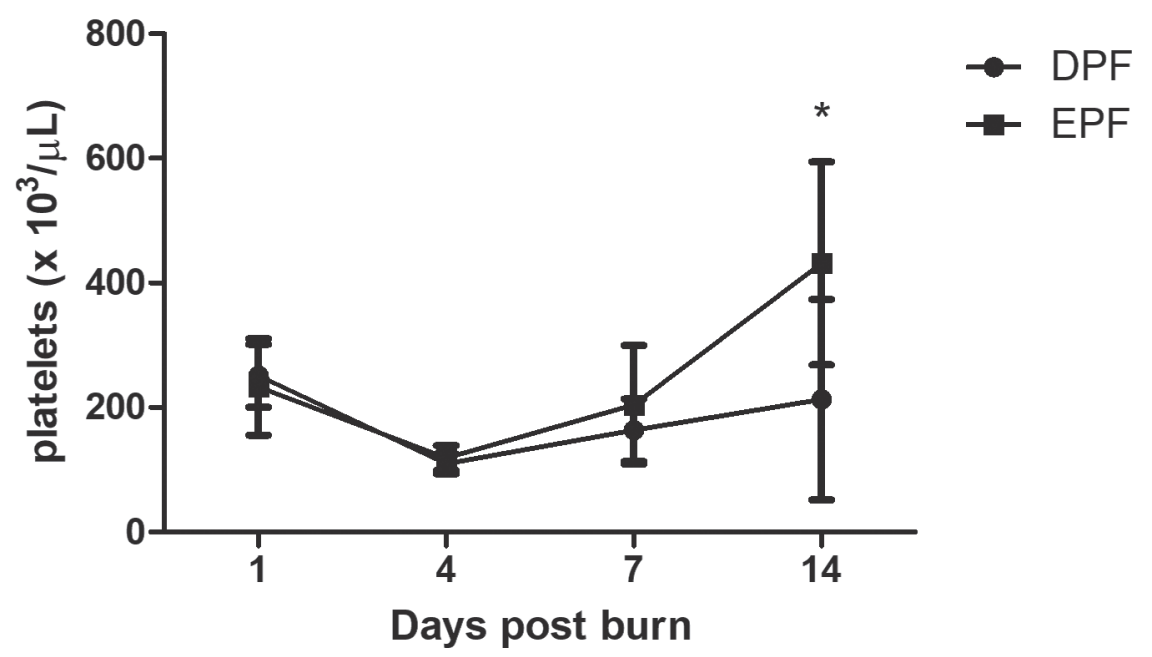

Fig. 4. Mean plasma platelet count change after burn injury.

A more noticeable increase in platelet count $\left(10^{3} / \mu \mathrm{L}\right)$ was observed on day 14 in the EPF group compared with the DPF group.

$* \mathrm{p}<0.05$ compared with the DPF group.

Table 3. Comparison of clinical outcomes between early post-pyloric feeding and delayed postpyloric feeding.

\begin{tabular}{lccc}
\hline Clinical outcomes & $\begin{array}{c}\text { Early Post-Pyloric Feeding } \\
\text { Group }(\mathrm{n}=5)\end{array}$ & $\begin{array}{c}\text { Delayed Post-Pyloric Feeding } \\
\text { Group }(\mathrm{n}=8)\end{array}$ & p value \\
\hline $\begin{array}{l}\text { ICU stay, Median } \\
\text { (days) }\end{array}$ & 34 & 40 & 0.828 \\
$\begin{array}{l}\text { Hospital stay, M } \pm \text { SD } \\
\text { (days) }\end{array}$ & $132 \pm 23$ & $144 \pm 70$ & 0.729 \\
$\begin{array}{l}\text { Blood stream infection } \\
(\%)\end{array}$ & $3(60.0)$ & $5(62.5)$ & 0.931 \\
$\begin{array}{l}\text { Pneumonia (\%) } \\
\text { Wound infection (\%) }\end{array}$ & $2(40.0)$ & $3(37.5)$ & 0.931 \\
\hline
\end{tabular}

$\mathrm{ICU}$, intensive care unit; $\mathrm{M} \pm \mathrm{SD}$, mean \pm standard deviation. 


\section{Discussion}

This study demonstrated that early introduction of post-pyloric feeding was beneficial to burns patients in the ICU with respect to nutritional and metabolic parameters; it also resulted in an increase in the platelet count of patients. Although a gastric ileus may occur in the immediate postburn period, the gut beyond the pylorus usually continues to function for the absorption of nutrients. The suggested procedure for early administration of enteral diet is through the pylorus by direct endoscopy (Chang et al. 1996; Lin et al. 2006). Through this procedure, the stomach is bypassed; therefore, any problems with respect to gastric emptying that could compromise adequate feeding are avoided.

The results of this study demonstrate that it is possible to successfully administer enteral feeding formulas through the pylorus within the first 24 hours after burn injuries. In addition, we observed that a high number of calories could be delivered using this method. Meanwhile, an increasing amount of tube feeding at a slower rate occurred when patients were administered post-pyloric tube feeding for $>24 \mathrm{~h}$.

Hypomagnesemia has received poor attention in medical literature than hyponatremia, hypokalemia, and hypocalcemia because of its lack of symptoms until plasma concentrations reach severely low levels (Pham et al. 2014). However, hypomagnesemia has been reported in severe burns patients and is associated with high mortality, need for mechanical ventilation, and length of ICU stay (Fairley et al. 2015; Upala et al. 2016). The involved mechanisms are likely multifactorial (Berger et al. 1997; Cunningham et al. 1987). We observed that the EPF group demonstrated a consistent rise in serum magnesium level. This result suggested that the initiation of EPF may serve to minimize magnesium malabsorption.

Platelets play an essential role in severe haemostasis disorders and immune response impairments in burns patients. Monitoring the platelet count is important during the resuscitation and care of severely burned patients (Gajbhiye et al. 2013). In critically ill patients, a blunted rise in platelet count has unfavourable prognosis (Nijsten et al. 2000). In the present study, the DPF group had a consistently slow rise in platelet count. The gradual rise in platelet count in the DPF group may be because platelet consumption is higher than platelet production. In addition, it may be possible that hypomagnesemia has a direct regulatory effect on platelet production (Rishi et al. 1990). To the best of our knowledge, the current study is the first to highlight the link between total serum magnesium levels and platelet count in burns patients. Therefore, to further improve outcomes in burned patients, future treatment should focus on targeted magnesium supplementation strategies based on the time course after burn injury.

There were some limitations in our study. First, this was a retrospective study with small sample size from a single medical center, there might be selection bias and residual confounding, which could potentially reduce the external validity. Second, all patients in our cohort were young adults, therefore, further investigation of the outcomes in middle age and elder population is required to validate the results. Finally, we did not consider the timing of administration of human albumin with respect to the interaction with actual nutrition intake. However, these results may aid in developing future clinical studies on the optimal timing and delivery of post-pyloric nutrition in burn patients.

In conclusion, based on the results of our retrospective study, post-pyloric feeding can be successfully initiated in severely burned patients after injury. The time interval between injury and the onset of post-pyloric feeding is the crucial factor. The critical threshold can be defined as less than 24 hours post-burn injuries. EPF allows for the provision of calculated caloric needs. However, our results are preliminary and need to be tested in a prospective randomized trial; our findings serve as an ethical background for such a study. Therefore, future studies that use our study findings as a background should be conducted to determine more effective treatment strategies.

\section{Acknowledgments}

Thanks to the support of the Civilian Administration Division of Tri-Service General Hospital, National Defense Medical Center, Taipei, Taiwan.

\section{Conflict of Interest}

The authors declare no conflict of interest.

\section{References}

Andel, H., Rab, M., Andel, D., Felfernig, M., Horauf, K., Felfernig, D., Schramm, W. \& Zimpfer, M. (2001) Impact of early high caloric duodenal feeding on the oxygen balance of the splanchnic region after severe burn injury. Burns, 27, 389-393.

Berger, M.M., Rothen, C., Cavadini, C. \& Chiolero, R.L. (1997) Exudative mineral losses after serious burns: a clue to the alterations of magnesium and phosphate metabolism. Am. J. Clin. Nutr., 65, 1473-1481.

Chang, W.K., McClave, S.A. \& Chao, Y.C. (2005) Simplify the technique of nasoenteric feeding tube placement with a modified suture tie. J. Clin. Gastroenterol., 39, 47-49.

Chang, W.K., Huang, W.H., Chao, Y.C., Tang, H.S. \& Hsu, C.T. (1996) Endoscopic nasoenteral feeding tube placement: a combined push and pull method. Gastroenterol. J. Taiwan, 13, 242-246.

Chen, Z., Wang, S., Yu, B. \& Li, A. (2007) A comparison study between early enteral nutrition and parenteral nutrition in severe burn patients. Burns, 33, 708-712.

Cunningham, J.J., Anbar, R.D. \& Crawford, J.D. (1987) Hypomagnesemia: a multifactorial complication of treatment of patients with severe burn trauma. JPEN J. Parenter. Enteral Nutr., 11, 364-367.

El-Solh, A.A. (2004) Clinical approach to the critically ill, morbidly obese patient. Am. J. Respir. Crit. Care Med., 169, 557-561.

Fairley, J., Glassford, N.J., Zhang, L. \& Bellomo, R. (2015) Magnesium status and magnesium therapy in critically ill patients: a systematic review. J. Crit. Care, 30, 1349-1358. 
Gajbhiye, A.S., Meshram, M.M. \& Kathod, A.P. (2013) Platelet count as a prognostic indicator in burn septicemia. Indian J. Surg., 75, 444-448.

Hettiaratchy, S. \& Papini, R. (2004) Initial management of a major burn: II-assessment and resuscitation. BMJ, 329, 101-103.

Lavrentieva, A., Kontakiotis, T. \& Bitzani, M. (2014) Enteral nutrition intolerance in critically ill septic burn patients. $J$. Burn Care Res., 35, 313-318.

Lin, H.H., Hsieh, T.Y., Chu, H.C., Wu, D.M., Chao, Y.C. \& Chang, W.K. (2006) Transpyloric tube feeding for 506 consecutive patients with delayed gastric emptying. J. Intern. Med. Taiwan, 17, 52-60.

Mosier, M.J., Pham, T.N., Klein, M.B., Gibran, N.S., Arnoldo, B.D., Gamelli, R.L., Tompkins, R.G. \& Herndon, D.N. (2011) Early enteral nutrition in burns: compliance with guidelines and associated outcomes in a multicenter study. J. Burn Care Res., 32, 104-109.

Nijsten, M.W., ten Duis, H.J., Zijlstra, J.G., Porte, R.J., Zwaveling, J.H., Paling, J.C. \& The, T.H. (2000) Blunted rise in platelet count in critically ill patients is associated with worse outcome. Crit. Care Med., 28, 3843-3846.

Pham, P.C., Pham, P.A., Pham, S.V., Pham, P.T., Pham, P.M. \& Pham, P.T. (2014) Hypomagnesemia: a clinical perspective. Int. J. Nephrol. Renovasc. Dis., 7, 219-230.

Raff, T., Hartmann, B. \& Germann, G. (1997) Early intragastric feeding of seriously burned and long-term ventilated patients: a review of 55 patients. Burns, 23, 19-25.

Rishi, M., Ahmad, A., Makheja, A., Karcher, D. \& Bloom, S. (1990) Effects of reduced dietary magnesium on platelet production and function in hamsters. Lab. Invest., 63, 717-721.

Sefton, E.J., Boulton-Jones, J.R., Anderton, D., Teahon, K. \& Knights, D.T. (2002) Enteral feeding in patients with major burn injury: the use of nasojejunal feeding after the failure of nasogastric feeding. Burns, 28, 386-390.

Sheridan, R.L. (2002) Burns. Crit. Care Med., 30, S500-514.

Stroud, M., Duncan, H. \& Nightingale, J.; British Society of Gastroenterology (2003) Guidelines for enteral feeding in adult hospital patients. Gut, 52 Suppl 7, vii1-vii12.

Trexler, S.T., Lundy, J.B., Chung, K.K., Nitzschke, S.L., Burns, C.J., Shields, B.A. \& Cancio, L.C. (2014) Prevalence and impact of late defecation in the critically ill, thermally injured adult patient. J. Burn Care Res., 35, e224-229.

Upala, S., Jaruvongvanich, V., Wijarnpreecha, K. \& Sanguankeo, A. (2016) Hypomagnesemia and mortality in patients admitted to intensive care unit: a systematic review and metaanalysis. QJM, 109, 453-459.

Vicic, V.K., Radman, M. \& Kovacic, V. (2013) Early initiation of enteral nutrition improves outcomes in burn disease. Asia Pac. J. Clin. Nutr., 22, 543-547. 